Supplement of Earth Syst. Dynam., 6, 45-59, 2015

http://www.earth-syst-dynam.net/6/45/2015/

doi:10.5194/esd-6-45-2015-supplement

(c) Author(s) 2015. CC Attribution 3.0 License.

(c) (1)

Earth System
Dynamics

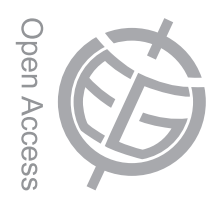

Supplement of

\title{
A multi-model analysis of change in potential yield of major crops in China under climate change
}

Y. Yin et al.

Correspondence to: Q. Tang (tangqh@igsnrr.ac.cn) 

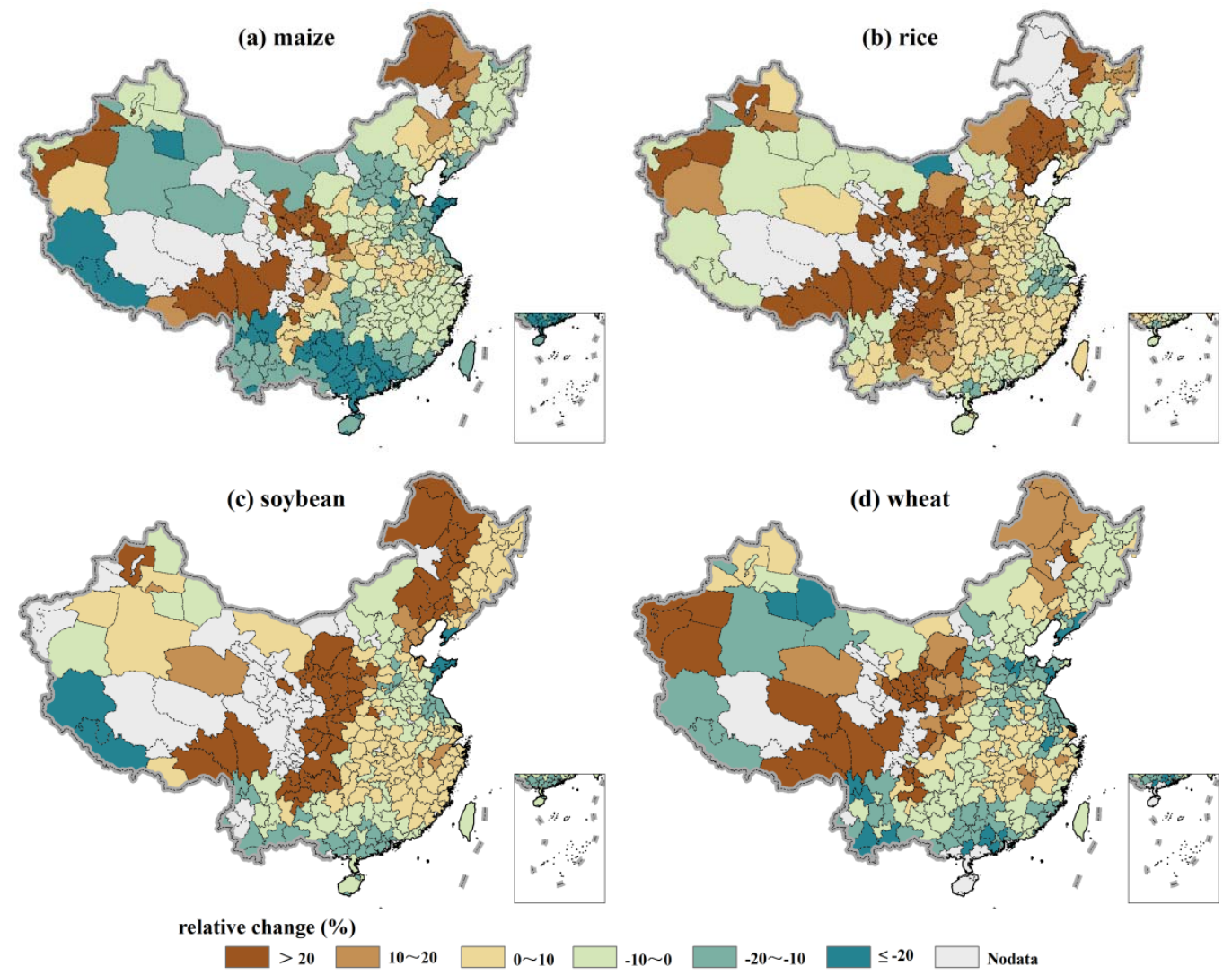

Fig. S1 The MMs of the relative change of the simulated yield of maize (a), rice (b), soybean (c), and wheat (d) with the $\mathrm{CO}_{2}$ effect at the end of the $21^{\text {st }}$ century (2070-2099) comparing with the simulated yield in the historical period (1981-2010) at the prefecture-level cities of China 

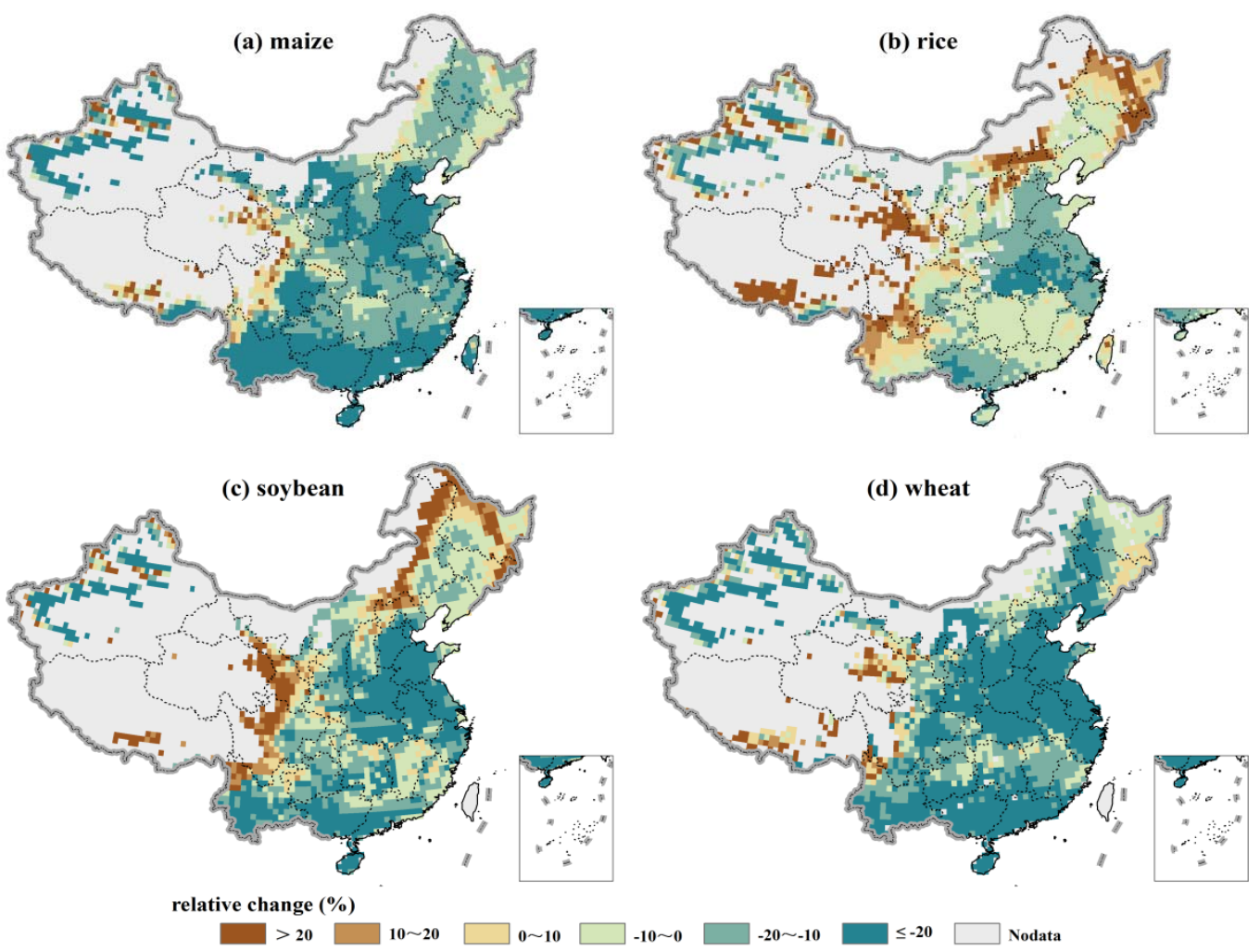

Fig. S2 The $25^{\text {th }}$ percentiles of the relative change of the simulated yield of maize (a), rice (b), soybean (c), and wheat (d) with the $\mathrm{CO}_{2}$ effect at the end of the $21^{\text {st }}$ century (2070-2099) comparing with the simulated yield in the historical period (1981-2010) 

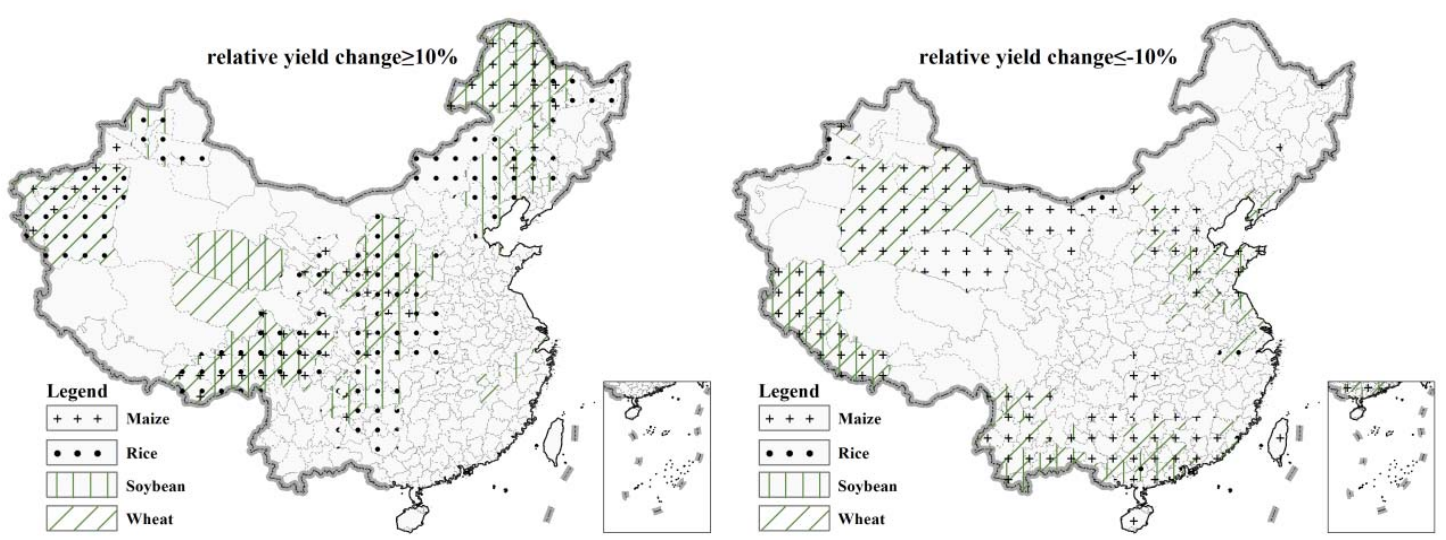

Fig. S3 The high climate resilience areas (left column) and high climate risk areas (right column) for the major crops in China at the prefecture-level cities 